\title{
Los fondos del museo de cerámica "Ruiz de Luna": una aportación a la historia de las lozas de Talavera y Puente
}

\author{
R. GARCÍA SERRANO*, D. PORTELA HERNANDO** y J. L. RENEO GUERRERO*** \\ *Museo Santa Cruz de Toledo y Ruiz de Luna de Talavera de la Reina \\ ** Arqueólogo, Miembro de la Asociación de Amigos del Museo Ruiz de Luna \\ ***Asociación de Amigos del Museo Ruiz de Luna
}

\begin{abstract}
Recorrido histórico de los orígenes del Museo de Cerámica de Talavera "Ruiz de Luna", la articulación de sus espacios y su diseño expositivo. La importancia de sus fondos a la hora de estudiar las producciones de Talavera - Puente en particular y para las lozas españolas en general. También se abordan otras cuestiones relativas a la Colección Permanente, los fondos visitables, los fondos de investigación y el crecimiento de su dimensión con su prolongación en el "Museo disperso".

Palabras clave: Colección monográfica. Exposición permanente. Fondos visitables. Fondos de investigación. Museo disperso. Loza. Azulejería.

The Ruiz de Luna Ceramic Museum. An a approach to the Talavera-Puente majoliques history

A historic approach of the origins of the Ceramic Museum "Ruiz de Luna" in Talavera de la Reina, the harmony of its space and its expositive design. The importance of its stored property when studying the productions of Talavera and Puente in particular, and all the Spanish pottery in general. Other items are also taken into consideration, especially those related to the Pemanent Collection, to the stored property opened to visitors, to the stored property of investigation and the growth of its dimension with its extension in the "disperse Museum".
\end{abstract}

Key words: Monographic collection, permanent exposition, stored property opened to visitors, stored property of investigation, disperse museum, pottery, tiles.

El Museo de Cerámica "Ruiz de Luna", abierto al público el 14 de Febrero de 1.996, y ubicado en el antiguo Convento de San Agustín, alberga en sus cuatro mil metros cuadrados y cuatro niveles, articulados en torno a dos claustros, una importante colección monográfica de cerámica de los alfares de Talavera y Puente de los siglos XVI al XX.

La colección, adquirida a la familia Ruiz de Luna en 1.963, fue formada principalmente en la primera mitad del siglo $X X$ por D. Juan Ruiz de Luna y Rojas, asesorado por el Padre Diodoro Vaca ( $H^{a}$ de la Cerámica de Talavera) y D. Platón Páramo, para disponer de modelos que reproducir en el alfar de Ntra. Sra. del Prado.

Esta colección, expuesta como museo-gabinete en el alfar de los Ruiz de Luna hasta 1.979, fue adquirida en 1.963 por la Dirección General de Bellas Artes, la Diputación Provincial y el Ayuntamiento, y constituye el grupo de piezas más numeroso del actual Museo.

En consonancia con las actuales tendencias expositivas, los fondos se han estructurado en tres grupos: la exposición permanente, el fondo visitable y otros materiales de investigación.

En la exposición permanente se muestran al público las principales piezas de las diferentes series y algunos paneles de azulejería, proponiendo un recorrido cronológico-artístico con espíritu didáctico, por la historia de la Cerámica de Talavera y Puente.

Los fondos visitables son consultados y visitados con cita previa.
La colección se completa con fragmentos y piezas reconstruidas procedentes de excavaciones arqueológicas realizadas en la ciudad en los últimos años.

El conjunto, en lo relativo a las lozas, ofrece muy buenos ejemplos de todas las series decorativas, si bien, por el carácter de la colección inicial, abundan las piezas populares y existen menos ejemplos de las producciones cultas que se pueden contemplar en otros museos, como el Arqueológico Nacional o el de Artes Decorativas. Destacan las series de influencias centroeuropeas, y las producciones del siglo XIX y XX, antes del resurgimiento cerámico talaverano representado en el Museo por piezas de los principales alfares talaveranos de principios de siglo.

En azulejería, aunque la mayor parte de la colección no está expuesta por falta de espacio - actualmente se está gestionando la ampliación del Museo con la Iglesia adyacente, del antiguo convento - se pueden contemplar magníficas obras, como el escudo de Santa Catalina, obra de A.Gaitán, fechado en 1.609 o los retablos de San Juan Bautista y la Anunciación, en la colección permanente, y en sus fondos visitables, en expectativa de tener espacio expositivo, frentes de altar, alizares, vírgenes del Prado, etc., que muestran una visión clara del uso de la cerámica como soporte pictórico y de su aplicación en la arquitectura del siglo XVI al XX. De la fábrica de Ntra. Sra. del Prado se puede admirar la fachada del antiguo Museo y el retablo de Santiago, obra inspirada en el monumento funerario de la madre del Cardenal Loaisa (siglo XVI). Con él se consigue un premio en 1.920 en la Exposición Nacional de 
Artes Decorativas de Madrid.

Estos fondos se completan con lo que se ha dado en llamar el "Museo disperso", formado en su entorno próximo por importantes conjuntos de azulejería distribuidos por la ciudad y sus alrededores.

En la Basílica de Ntra. Sra. del Prado, "capilla sixtina" de la azulejería talaverana, destacan, además de los repertorios iconográficos sobre la vida de Jesús, genealogía de la Virgen, etc., otros conjuntos de azulejos de edificios religiosos desaparecidos, entre los que destacan el importantísimo de San Antonio Abad, su retablo y escultura.

Las iglesias de cercanos pueblos, como Piedraescrita, Mombeltrán, El Casar, o las ermitas de la Virgen de Gracia en Velada (foto 13) y San Illán en Cebolla... completan el importante conjunto conservado de las producciones azulejeras de la ciudad conocida como de la cerámica, estableciendo un diálogo entre los fondos del Museo Ruiz de Luna y el Museo Disperso, y creando lazos de unión entre investigación, función, obra atesorada y en uso.

Después de cerrar, por amenaza de ruina, el antiguo "museo-gabinete" en 1.979, que aún se encontraba en el antiguo "Alfar de Ntra. Sra. del Prado" (1.908-1.961), la colección pasó por diferentes almacenes, donde, cubierta de polvo y secuestrada, permanecería hasta 1.993.

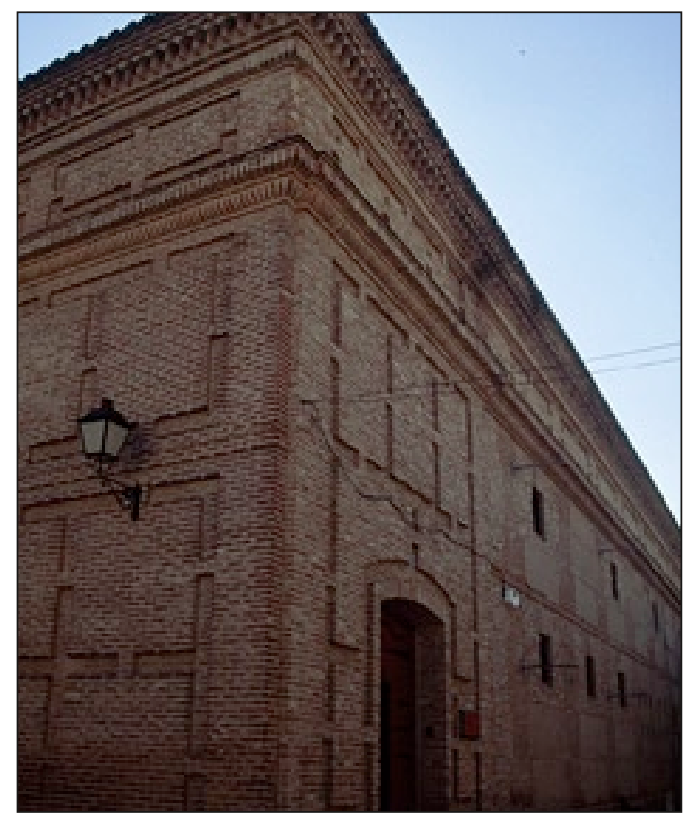

Fot. 1 Vista exterior del Museo

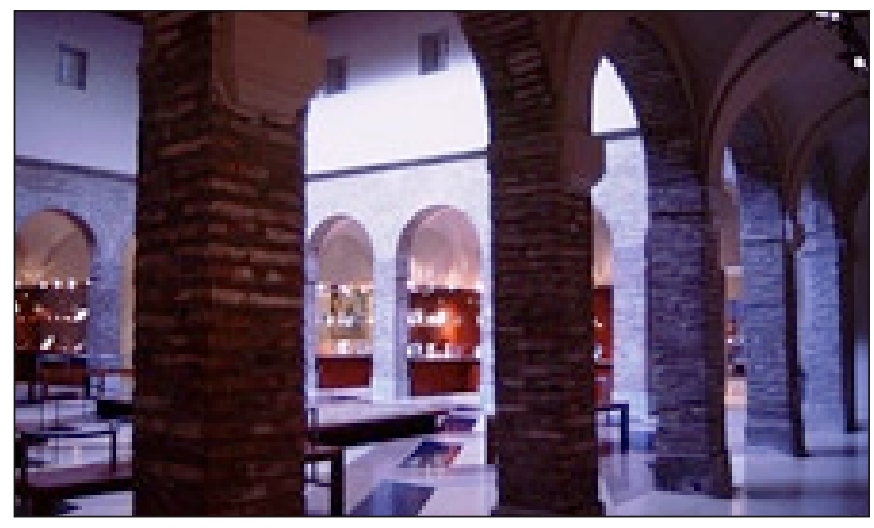

Fot. 3 Sala de exposición permanente
La elección de un nuevo lugar para su exposición pública, después de barajar numerosas posibilidades, recayó en el antiguo convento de San Agustín, casa madre de los agustinos recoletos (foto 1).

El edificio se encuentra situado en el cuerpo principal de la villa, junto al alcázar e intramuros y fue construido por el arquitecto Fray Lorenzo de San Nicolás (1.595-1.679), en el segundo cuarto del siglo XVII, según las normas y el estilo reflejado en su obra, de gran influencia posterior, "Arte y uso de la arquitectura" (1633-1634).

El edificio, construido en ladrillo, consta de dos partes diferenciadas: el convento y la Iglesia. La zona conventual, antiguas escuelas de San Agustín, propiedad municipal, fue la parte adaptada para albergar la colección, y es actualmente el Museo.

El templo, de propiedad particular, adosado al convento, es la ampliación lógica del Museo, y cuando terminen las negociaciones, y su adaptación, el espacio de exposición de la azulejería (foto 2).

La intervención sobre el convento, que se encontraba en ruina parcial, respetó principalmente las fachadas exteriores el claustro y los sótanos, creando otros espacios adaptados a las necesidades que demandaba el nuevo uso del edificio.

El proyecto de rehabilitación se encomendó a los arquitectos D. Manuel Barbero y a D. Carlos Picardo.

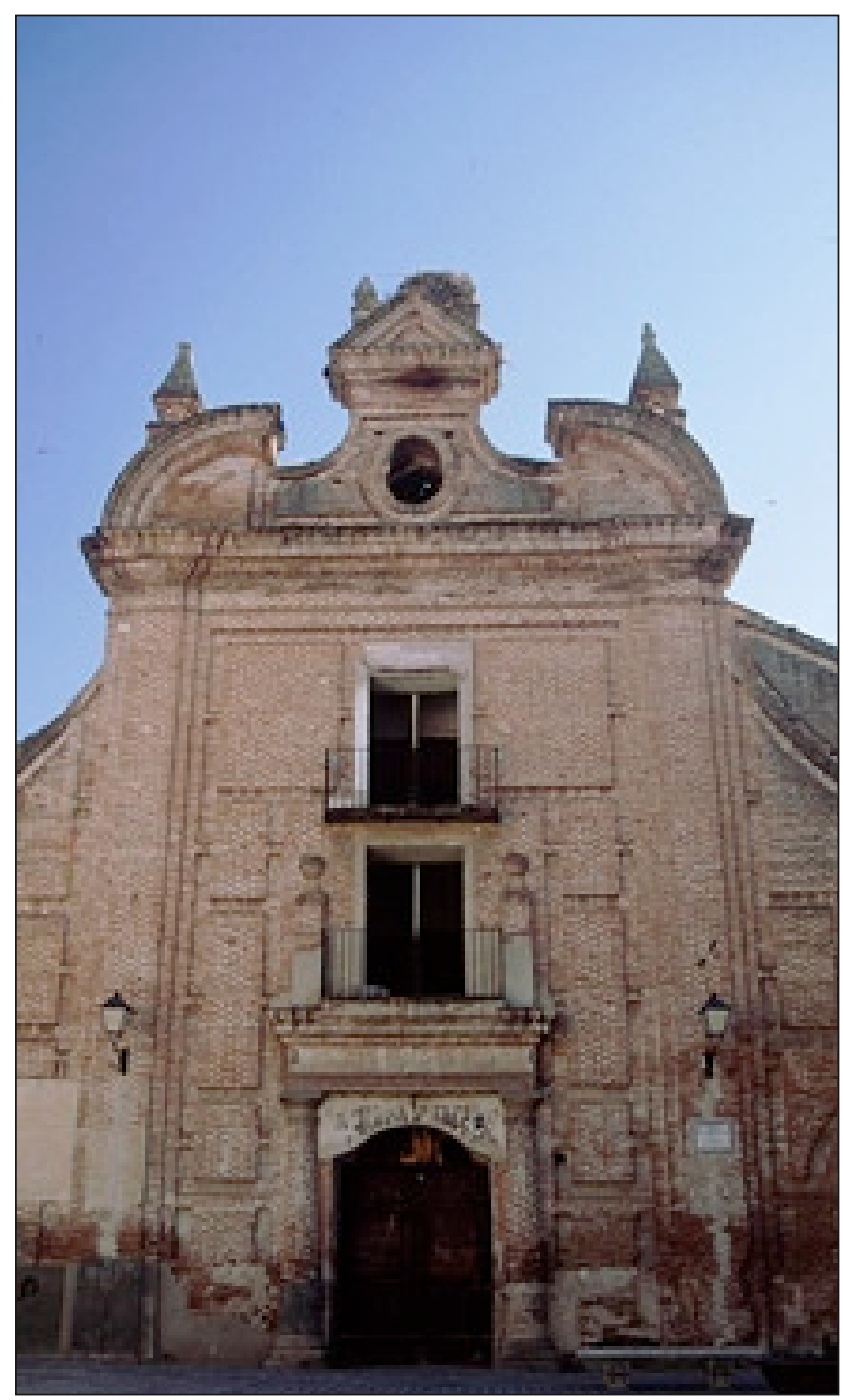

Fot. 2 Fachada Iglesia de San Agustín, ampliación del Museo 
Sin entrar en grandes detalles, articularon la organización funcional por niveles. En el sótano almacenes y sala de arqueología. En la planta baja exposición permanente, zona de carga y descarga, conserjes, recepción, etc. En la primera el salón de actos, la sala de exposiciones temporales, el almacén interno y el visitable. En la segunda ubicó la biblioteca, la sala de restauración, el laboratorio de restauración y el fotográfico, los espacios dedicados a dirección y administración y la sala de los Amigos del Museo.

A la muerte de D. Manuel Barbero, se encargaron los trabajos restantes: instalación de la exposición permanente, amueblamiento, equipamiento y algunas reformas estructurales, como la construcción de un nuevo cuerpo de escaleras y el diseño de la sala de audiovisuales, a D. Manuel Serrano Marro y a Da. Marta Rodríguez Ariño.

La sala de arqueología en la planta sótano aprovecha la antigua bodega del convento, un gran espacio, con bóveda de medio cañón, construida en ladrillo (foto 6).

En ella se exponen algunos restos arqueológicos en piedra, columnas, capiteles, pilastras, cupas, estelas..., y una muestra de piezas cerámicas desde el siglo I al XI, aparecidas en las diferentes excavaciones arqueológicas realizadas en la ciudad en los últimos años. La sobriedad del espacio y la tenue iluminación dan al visitante la posibilidad de comunicarse íntimamente con los objetos expuestos, como si de un santuario o cripta se tratase.

La exposición permanente, en la planta baja, está articulada en torno a los dos claustros. En el primero, que conserva parte de la fábrica antigua, y un aspecto conventual, se exponen lozas del siglo XVI y XVII, suelos del siglo XX y una colección de cerámica moderna de los Ruiz de Luna que han continuado en la profesión. Las vitrinas están montadas en las galerías interiores y se separan del centro por arcos de medio punto, en ladrillo (foto 3).

Los suelos de terrazo coloreado, construidos "in situ", for-

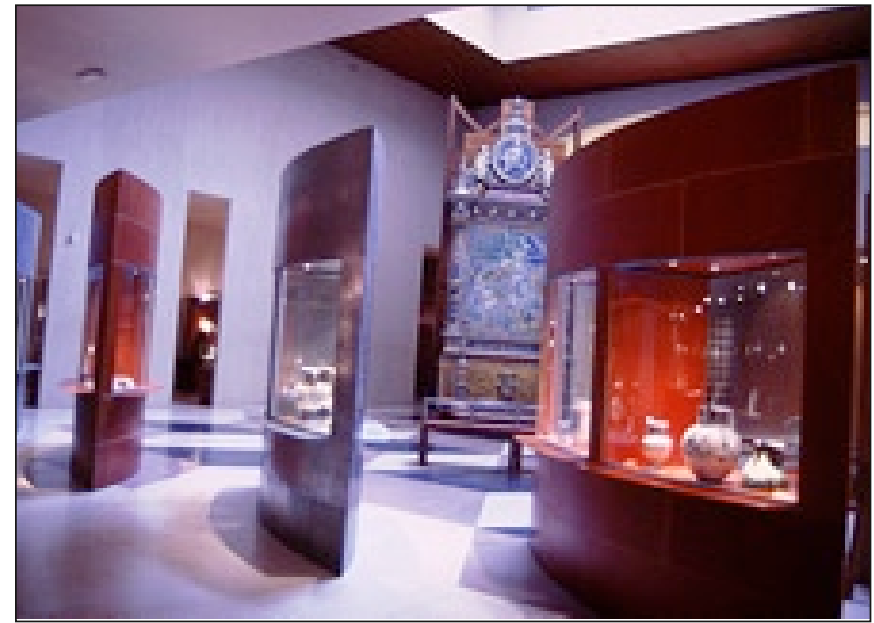

Fot. 5 Sala de exposición permanente

man un dibujo geométrico, inspirado en el Palacio de los Dogos de Venecia.

El segundo claustro, de nueva construcción, es sencillo, de formas lisas, con ángulos pronunciados.

La disposición de las vitrinas es perimetral, con pasadizos intimistas. En el centro se exponen piezas muy interesantes, como el "Gaitán", la fachada del antiguo Museo y el Retablo de Santiago, exento, montado sobre un gran atril de más de seis metros, inspirado en las máquinas utilizadas en arquitectura en el Renacimiento (foto 5).

Los materiales utilizados, vidrio, acero, aluminio, chapa galvanizada, madera, hierro... y el moderno diseño de su mobiliario, dan al conjunto una agradable armonía, invitando a su contemplación (foto 4).

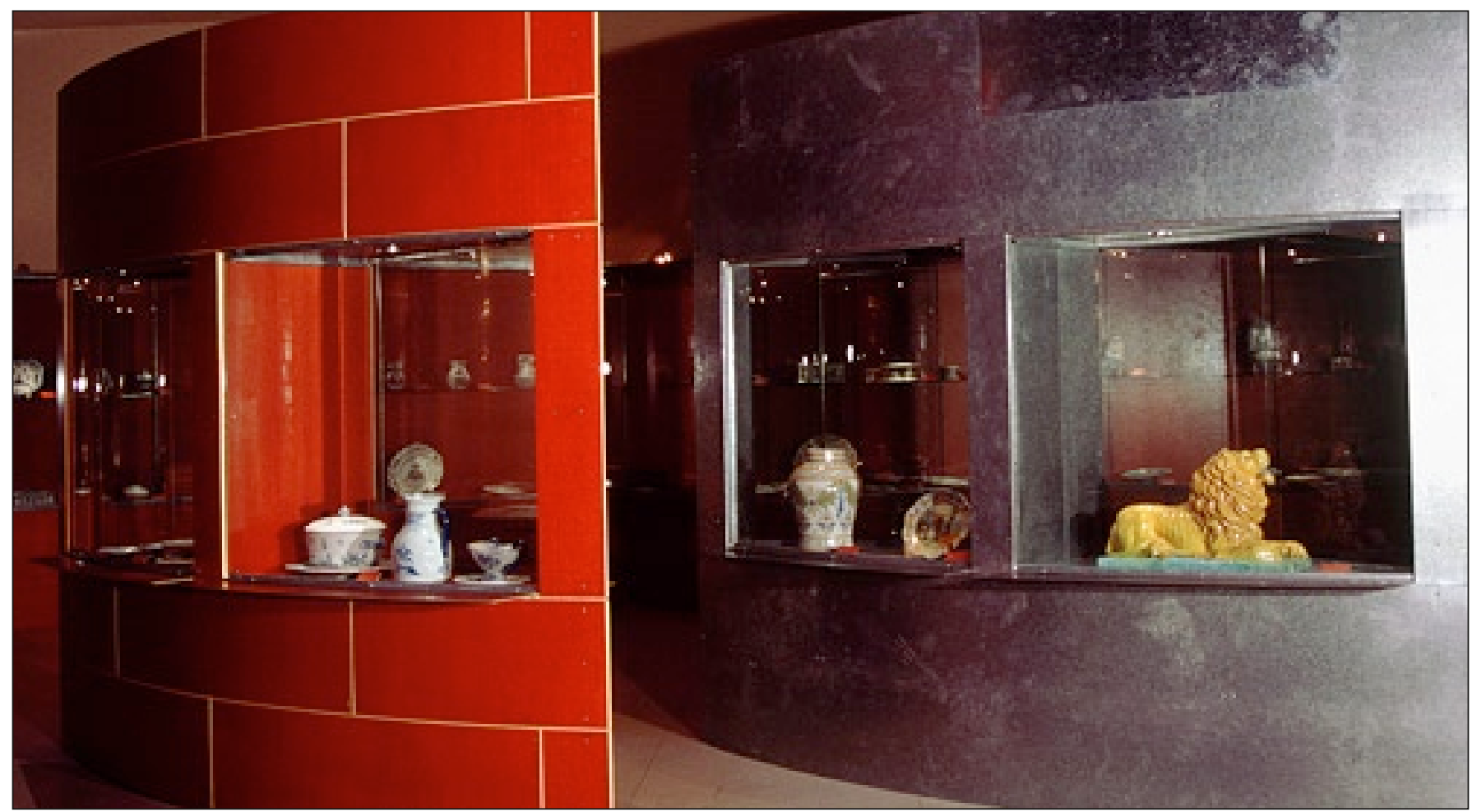

Fot. 4 Sala de exposición permanente 
Los almacenes visitables, con las piezas ordenadas por épocas y estilos, en armarios independientes, permiten su visualización y estudio sin ninguna complicación. Dos grandes arcos comunican este almacén y la Sala de Exposiciones Temporales con el segundo claustro, permitiendo establecer una relación constante entre exposición temporal, estudio e investigación con las piezas expuestas de la colección, invitando a su visualización desde otra perspectiva.

La colección del museo, formada por unas 1.500 piezas entre lozas y azulejería, distribuidas en las mencionadas exposición permanente, y fondos visitables, está constituida principalmente por la "Colección Ruiz de Luna" formada en 1.908 a 1.961, con la incorporación posterior de algunas importantes obras como el retablo de la Inmaculada, San Francisco y San Antonio, (203 x $234 \mathrm{~cm}$.) del siglo XVII, procedente del convento de la Madre de Dios, o la fachada de la tienda del Alfar de Montemayor de 1.922, que mide más de 6 metros de alto por $4^{\prime} 5$ de ancho, con motivos renacentistas, de grutescos, angelotes, alegorías y relieves, coronada por una interesantísima crestería con máscaras y dragones y una crátera exenta central.

En piezas de evolución, dos jarrones azules del siglo XVII, y piezas de los siglos XVI al XX, forman los actuales fondos propios y la colección.

En ella están representadas todas las series producidas en los alfares de Talavera -Puente, de los siglos XVI al XIX, en lo

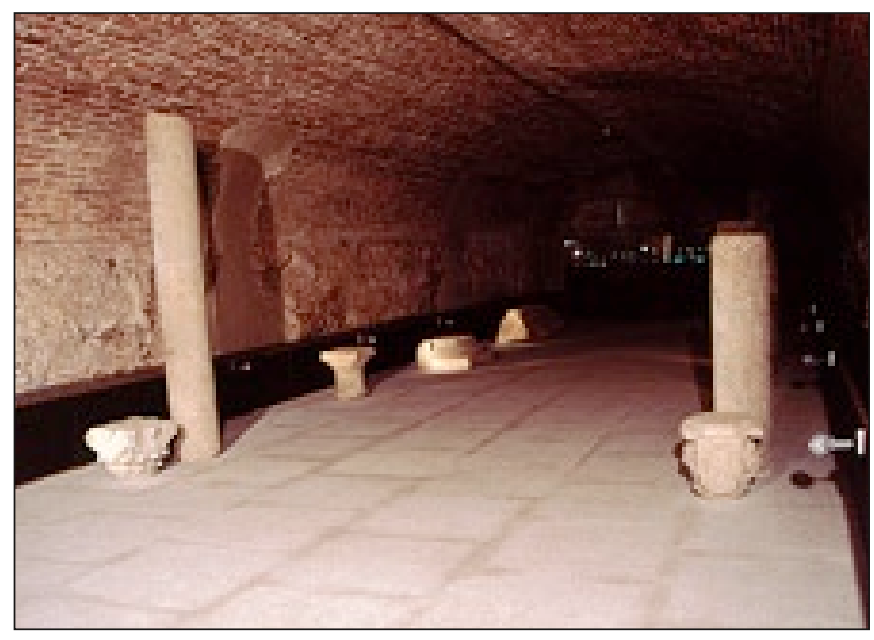

Fot. 6 Sala con una muestra de materiales arqueológicos

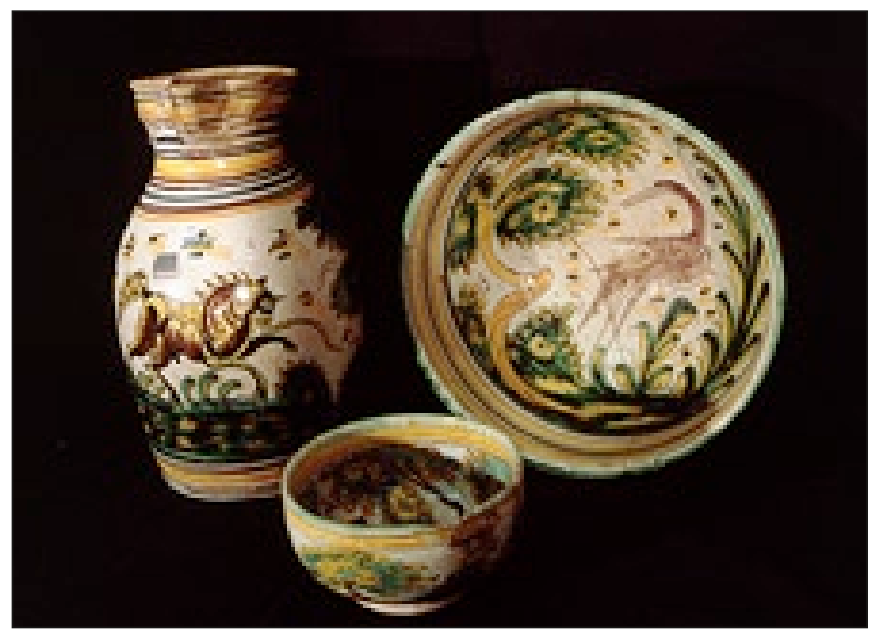

Fot. 8 Piezas de la serie Polícroma (siglos XVII / XVIII) relativo a su decoración, y un amplio abanico en lo relativo a las formas.

Respecto a la loza, dentro de las producciones del siglo XVI y XVII, de la serie de "Mariposas" se dispone de un amplio catálogo de motivos, geométricos, vegetales y zoomorfos (conejos, búhos, gacelas...), acompañados de los que definen la serie (mariposas, florecillas y círculos).

De la serie "Tricolor" y de la "Encomienda o Estrella de Plumas", motivos en azul, naranja y manganeso, se conservan piezas de sus diferentes estilos compositivos, disponiendo de muchos de sus motivos, aunque no de todos, por su amplio repertorio y su pronta apreciación como pieza de colección (foto 9).

De la serie "Esponjillada, goteada o salpicada", dada su escasez, el museo dispone de muy pocas piezas, pero suficientes para su muestra y representación.

De la serie de "Ferroneríes" o "Recortes", no se dispone de piezas de evolución, pero está representada en varios paneles como el de San Juan Bautista o el de la Crucifixión (fotos 11 y 12). De la serie "Punteada Polícroma" y "Punteada Azul" aunque no hay piezas enteras, sí existen fragmentos, localizados en excavaciones arqueológicas en la ciudad, que confirman a Talavera como su centro productor.

De los siglos XVII y XVIII de las series chinescas, "Helechos", "Hojas de Palma", "Golondrinas"..., el museo dispone de una excelente colección, en la que están representadas las piezas

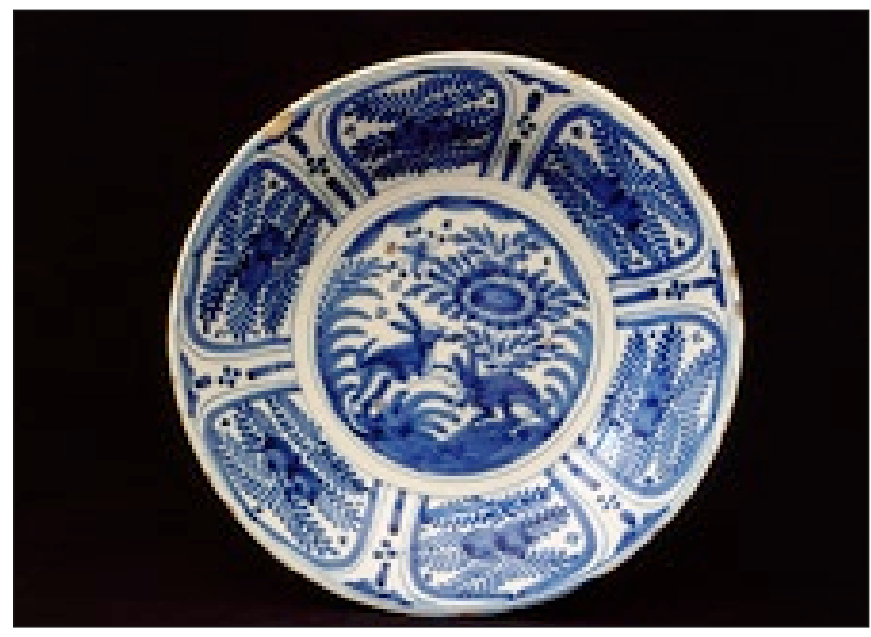

Fot. 7 Plato de la serie de Helechos (siglos XVII / XVIII)

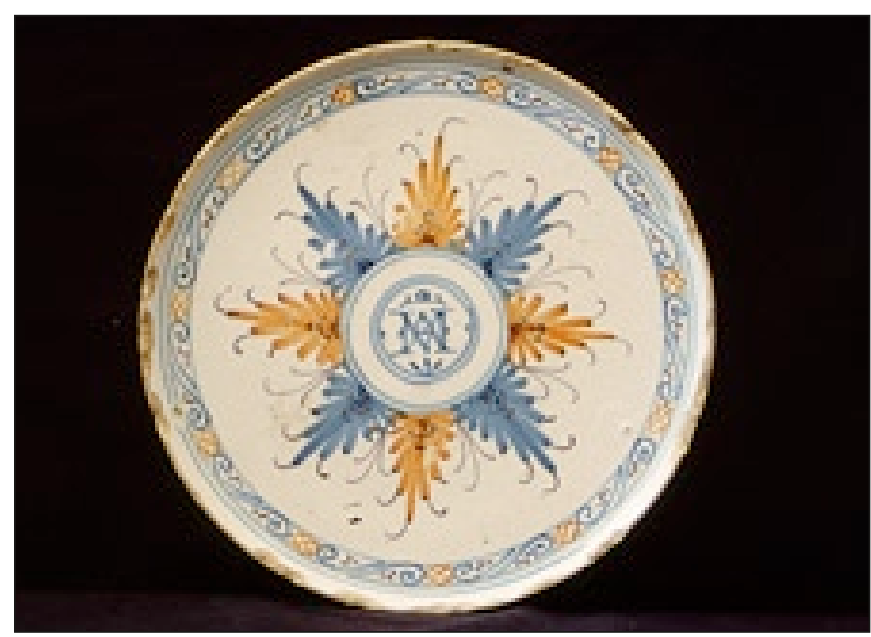

Fot. 9 Salvilla de la serie de la Estrella de Plumas o Encomienda (siglo XVIII) 
tipos y algunas con variantes tanto en sus motivos como en su composición (foto 7).

Una de las series mejor representada es sin duda la serie "azul", de la que destacan los juguetes y las piezas de vajilla con motivos arquitectónicos, fantásticos, mitológicos, zoomorfos, vegetales, antropomorfos... la orza con escudo de la inquisición, el conjunto de albarelos, los Aguamaniles etc. , muchas de ellas piezas de excepción (foto 10).

De la serie polícroma, la representación es menor, aunque hay expuestas magníficas piezas, como la benditera de la serie de la "Flor de la Patata", o los tinteros de encargo, con el nombre del propietario y la flecha de su fabricación (foto 8).

Las series hasta ahora mencionadas, se producían en un momento en el que Talavera era uno de los principales centros de producción y difusión de las lozas estanníferas, dentro de España y en el exterior. Sus formas, diseños y motivos se copiaban e interpretaban en otros centros alfareros, hasta el punto de identificar y denominar a estos productos como "las talaveras", independientemente de su lugar de fabricación.

El cambio de gusto por lo centroeuropeo y la creciente importación de lozas, principalmente francesas, dió como resultado la creación por el Conde de Aranda, en 1.727, de la Real Fábrica de Alcora, que en muy poco tiempo se convirtió en el centro irradiador de los nuevos estilos, formas y motivos, más acordes con la demanda interior.

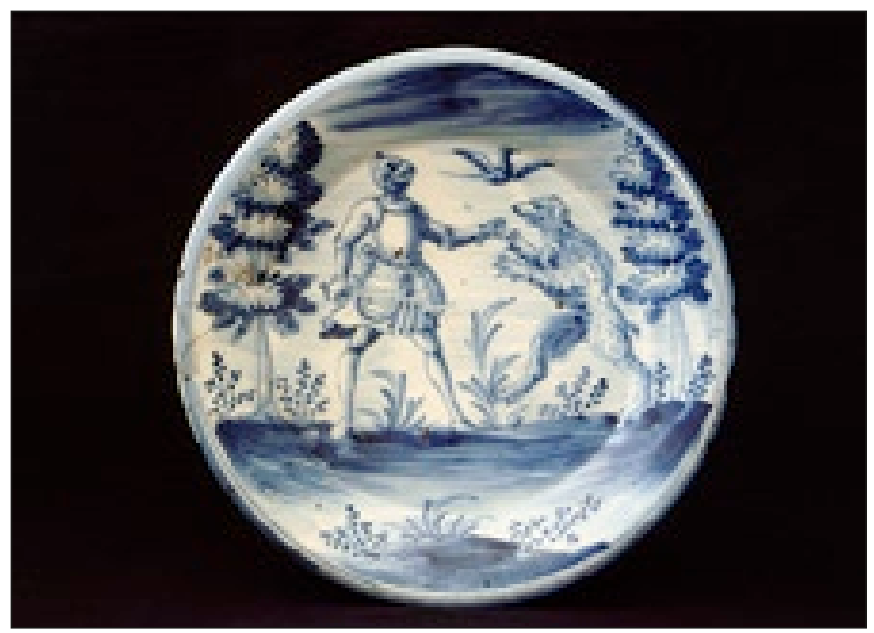

Fot. 10 Plato de la serie Azul (siglo XVII)

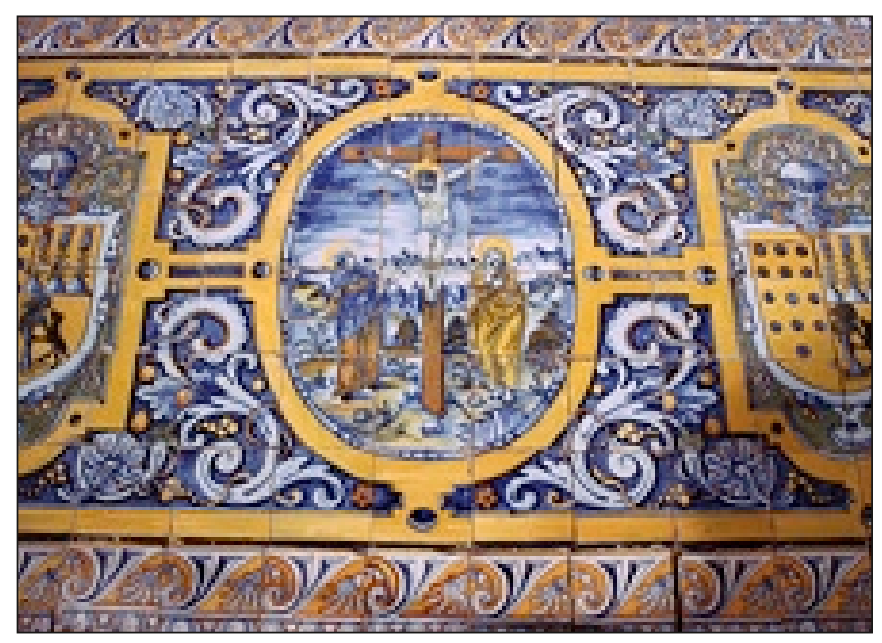

Fot. 12 Frente de altar (siglo XVI)
Esta nueva concepción, que desplazó a las clásicas series talaveranas, permitió por otra parte el desarrollo de una nueva producción inspirada en los motivos alcoreños, pero con carácter propio y dirigida a un amplio sector de la población. Nacen así las series de la "Adormidera", "Los claveles", "la Puntilla de Berain", "El Chaparro", "El Ramito", la "Virgen del Prado", "Guirnaldas y Pabellones", la del "Pino" y la "Cola del gallo".

De todas estas series, el museo tiene una gran colección y, aunque adolece de piezas excepcionales, dispone de piezas suficientes para desmentir la decadencia de Talavera como centro productor y confirmar la continuidad en la calidad de sus productos cerámicos, tanto en lo relativo a las formas como en su decoración, manteniendo una gran originalidad en su producción.

De las series de la "Pajarita", "Bandas concéntricas" y "Guerra de la Independencia", que comienzan en el siglo XIX, tenemos una magnífica representación.

Del siglo XX, menos representada, hay piezas de la fábrica de Ntra. Sra. del Prado: vajillas, candeleros, esculturas, piezas de muestrario...; del Carmen, vajilla principalmente y alguna pieza modernista de Montemayor.

Los fondos de azulejería están formados por olambrillas, verduguillos, placas, azulejos, molduras, relieves y alizares, utilizados en solerías, arrimaderos, frentes de altar, retablos, cementerios, oratorios, escaleras, fachadas...(foto 11).

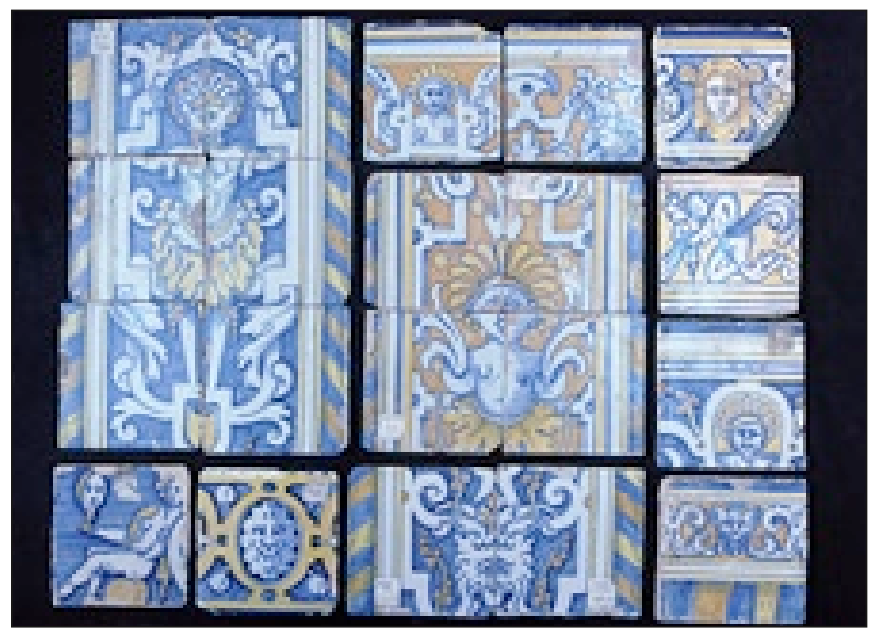

Fot. 11 Conjunto de azulejos (siglo XVI)

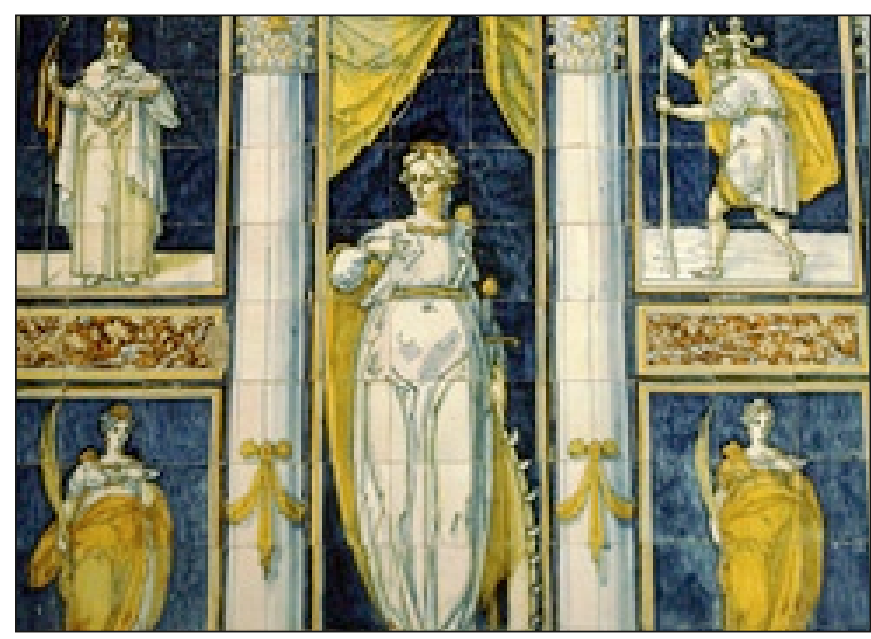

Fot. 13 Ermita de Gracia, Velada. Retablo de Santa Catalina. Siglo XVI. 
De producciones no talaveranas, el museo dispone de una muestra de azulejos, verduguillos y olambrillas con motivos geométricos de fabricación toledana en cuenca o arista, y algunos alizares de cuerda seca, con motivos renacentistas.

Ya de los alfares talaveranos se conservan importantes conjuntos de azulejería del siglo XVI, entre los que destacan el retablo de San Juan Bautista y la Anunciación, en la exposición permanente.

En los fondos, el panel de San Sebastián, el del Dios Pan, el Santiago Matamoros y el frente de altar de San Blas, Santa Catalina y Santa Lucía.

Del siglo XVII, la pieza más importante es el Escudo de Santa Catalina, expuesto en el segundo claustro, por encontrarse firmada por Alonso Figueroa y Gaitán y estar fechado en 1.609; en calidad le sigue el retablo de La Inmaculada, San Francisco y San Antonio.

Del siglo XVIII, el conjunto de paneles del Pelícano, reconstruido por Ruiz de Luna, partiendo de muy pocos azulejos originales, y la colección de vírgenes del Prado, firmadas y fechadas, que permiten estudiar, junto con las conservadas en la Basílica de Ntra. Sra. del Prado, su evolución iconográfica.

Del siglo XX, son de destacar la fachada de la Trinidad realizada en 1.920 en el alfar de Montemayor, el escudo de Toledo del alfar de Ntra. Sra. del Prado de 1.918, realizado con técnica mixta, cuerda seca y mayólica, el zócalo de zaguán de Guijo, la chimenea monumental de Ruiz de Luna, el ángel de Mariano Benlliure, con molde de Vicente Camps, la fachada del antiguo Museo-Alfar de Ruiz de Luna, y el retablo de Santiago (foto 5).

También existen piezas sueltas de retablos, paneles de azulejería de repetición de zócalos y arrimaderos, y frentes de altar de "tapiz", imitando telas, principalmente de los siglos XVI, XVII y XVIII, que confirman la importancia de la azulejería y su temprano desarrollo en este centro alfarero.

Este actual y moderno museo monográfico de las producciones de loza de Talavera de la Reina y Puente del Arzobispo del siglo XVI al XX, que nació de una modesta colección de "cacharros viejos", es hoy un punto imprescindible para comprender la historia de las cerámicas de los dos centros alfareros. Un lugar ideal dadas sus características, conjunto no homogéneo, abundancia de piezas populares y defectuosas, piezas poco representadas o ausentes en otras colecciones, variedad y representación de la evolución de las lozas de

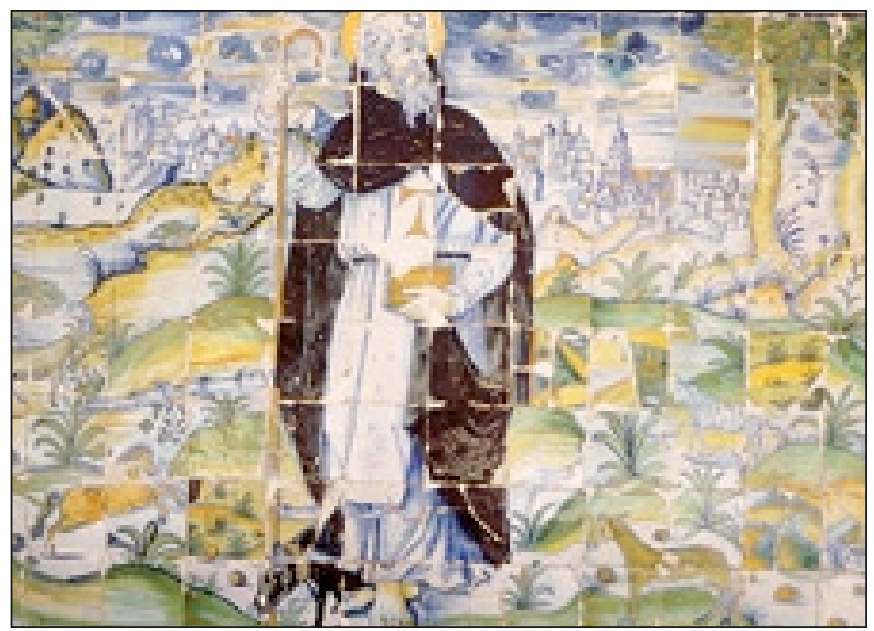

Fot. 14 Basílica de Nra.Sra. del Prado, Talavera. Panel de San Antón. Siglo XVI
Talavera - Puente, importante catálogo de motivos, firmas, marcas, fechas..., para profundizar en su conocimiento.

El "museo disperso" por la Ciudad y su entorno, permite por otra parte estudiar, contemplar, y ampliar los conocimientos adquiridos.

En la parroquia de San Andrés, se conservan magníficos frentes de altar de "tapiz" del siglo XVI, un panel de San Andrés y un aguamanil con su soporte del siglo XVII.

En la capilla del Cristo de los Mercaderes, en la Corredera, un frente de altar. En la parroquia de San Francisco, dos escudos, un panel de San Francisco estigmatizado del siglo XVI y XVII, y un vía crucis en relieve del siglo XX.

En la Colegial, el frente de altar de los evangelistas y el de tapiz del siglo XVI y los retablos del Cristo del Mar, inspirado en el de Santiago que conserva el Museo, y el de Santa Justa y Santa Rufina, ambos de Ruiz de Luna.

También son dignos de visitarse los paneles de la Anunciación y San Bernardo, en la fachada del convento del mismo nombre.

La Basílica de Ntra. Sra. del Prado, es punto y aparte, ya que conserva una impresionante colección de azulejería de los siglos XVI al XX.

En el atrio, escenas de la vida de Jesús, de San Antón (foto 14), escudos heráldicos, diversas iconografías de santos, escenas del antiguo testamento, azulejos de repetición, etc. En los muros exteriores, vírgenes del Prado y escudos principalmente. En el interior, en un zócalo corrido, que ocupa las dos naves laterales, escenas de la genealogía de la virgen, de la vida de Jesús y de San Antón. En sus paredes los retablos de San Lorenzo y el de San Antón Abad, de más de 6 metros, cuya escultura exenta en cerámica estannífera, la realizó Juan de Alburquerque, en Talavera, en 1.571, el primer talaverano con obra firmada conocida.

En las Sacristías numerosos azulejos, un aguamanil y un zócalo corrido de 1.761, firmado por Moya. De loza en el tesoro se conservan aguamaniles, bandejas, palanganas, ánforas, violeteros y placas, entre otras piezas de indudable interés.

Del "renacimiento cerámico de principios de siglo" cabe mencionar la fachada y el patio de la Tortuga (Ruiz de Luna, 1.912), la fuente y el conjunto de los jardines del Prado, la fachada del Bar Pilar (foto 15), la fuente del Mercado, la Plaza del Pan y San Prudencio.

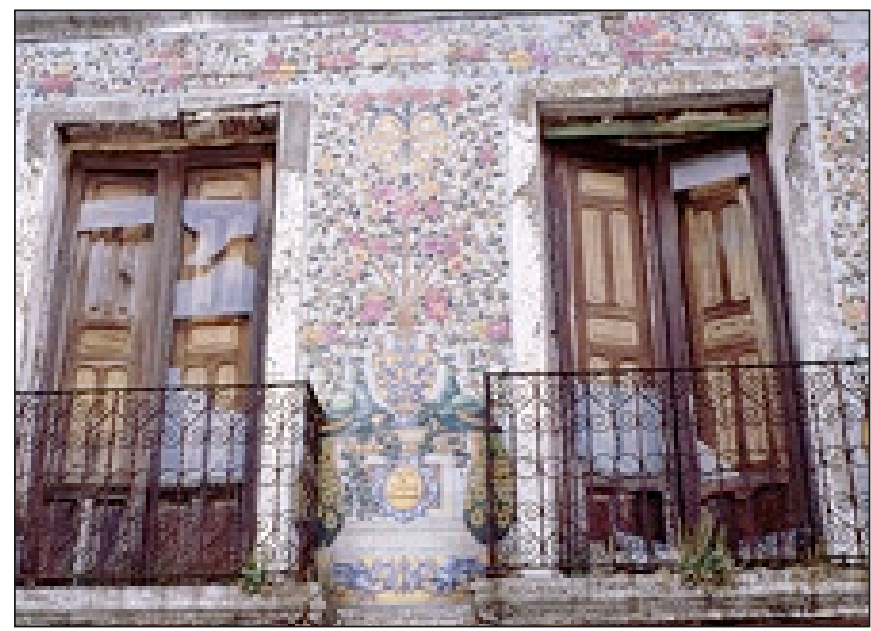

Fot. 15 Bar El Pilar, Talavera. Alfar de Ruiz de Luna. 1er. cuarto del siglo $\mathrm{XX}$ 